\title{
Üniversiteli Gençlerin Günde İçilen Sigara Sayısına Göre Nikotin Bağımlılı̆̆ı ve Solunum Fonksiyonlarının Karşılaştırılması
}

\author{
Comparison of Nicotine Dependence and Pulmonary Function of \\ University Students According to the Number of Cigarettes Smoked per \\ Day
}

\author{
Benil KISTAK ALTAN* iD \\ İlhan ODABAŞ ${ }^{* *}$ iD
}

Öz

Çalışmanın amacı üniversiteli gençlerde günde içilen sigara sayısına göre nikotin bağımlılığının ve solunum fonksiyonlarının karşılaştırılmasıdır. Çalışmaya beden eğitimi ve spor yüksekokulunda eğitim gören 15 kadın 15 erkek toplam 30 öğrenci gönüllü olarak katıldı. Katılımcıların özellikleri kişisel bilgi formu ile nikotin bağımlılı̆̆ ise Fagerström nikotin bağımlılık anketi ile değerlendirildi. Solunum fonksiyonlarından; zorlu vital kapasite, zorlu ekspirasyon hacmi, tepe akım hızı COSMED-Pony FX spirometre ile ölçüldü. Cinsiyet ve günde içilen sigara sayısına göre farklılık için Mann-Whitney U test; çoklu değişkenlerin değerlendirilmesinde ise çoklu lineer regresyon modeli uygulandı $(\mathrm{p}<0.05)$. Solunum fonksiyonlarında ve nikotin bağımlılı̆̆ında gruplar arası anlamlı farklılık bulunmazken ( $>>0.05)$; günde 6 ve daha fazla sigara içen grupta sadece zorlu vital kapasite değerinde cinsiyet etkisinin olduğu belirlendi $(\mathrm{p}<0.05)$. Katılımcıların solunum fonksiyon cevapları üst seviyede olup nikotin bağımlılıkları ise çok az ve az bağımlıydı. Günde içilen sigara sayısı artmasının nikotin bağımlılığında ve zorlu vital kapasitede olumsuz etki yarattığı gözlendi.

Anahtar Kelimeler: Sigara içimi, nikotin bağımlılı̆̆ı, solunum fonksiyonu, genç.

\section{Abstract}

The aim of the study is to compare nicotine dependence and pulmonary functions in university students according to the number of cigarettes smoked per day. A total of 30 students, 15 women and 15 men, studying at a physical education and sports school participated in the study voluntarily. The characteristics of the participants were evaluated with the personal information form and the nicotine dependence was evaluated with the Fagerström nicotine dependence questionnaire. From pulmonary function; forced vital capacity, forced expiratory volume, and peak flow rate were measured with the COSMED-Pony FX

* Öğr. Gör., Haliç Üniversitesi, Beden Eğitimi ve Spor Yüksekokulu, İstanbul, benilkistak@halic.edu.tr, https://orcid. org/0000-0002-5868-6856

** Doç. Dr., Haliç Üniversitesi, Beden Eğitimi ve Spor Yüksekokulu, İstanbul, ilhanodabas@halic.edu.tr, https://orcid. org/0000-0002-4578-5142 
spirometer. Mann-Whitney U test for difference according to gender and number of cigarettes smoked per day; Multiple linear regression model was used to evaluate multiple variables $(\mathrm{p}<0.05)$. While there was no significant difference between the groups in pulmonary function and nicotine dependence $(\mathrm{p}>0.05)$; It was determined that there was only a gender effect on the forced vital capacity in the group that smoked 6 or more cigarettes per day $(\mathrm{p}<0.05)$. The pulmonary function responses of the participants were at a high level and their nicotine dependence was very low and less dependent. It was observed that the increase in the number of cigarettes smoked per day had a negative effect on nicotine dependence and forced vital capacity.

Keywords: Cigarette smoking, nicotine dependence, pulmonary function, youth.

\section{GíRiș}

Tüm dünyada ve ülkemizde yaygın olan sigara bağımlılığı, özellikle kalp ve akciğer hastalıklarının oluşumunda etkin rol oynamaktadır. Sigara kullanımı ile üst solunum yolları hastalıkları arasındaki ilişki belirlenip günümüzde de bu ilişkinin varlığı epidemiyolojik çalışmalarla gösterilmektedir (Thacher ve diğ., 2018). Dünya Sağlık Örgütü’nün raporlarında ülkelerin yaklaşı \%60’ında 2010 yılından itibaren tütün tüketiminde düşüş yaşandığı bildirilmesine rağmen Türkiye bu ülkeler arasında yer almamaktadır (WHO, 2021). Ayrıca özellikle az gelişmiş ve gelişmekte olan ülkelerde, öğrencilerin sigara içme oranı daha yüksek saptanmıştır (Karlıkaya ve diğ., 2006). Maalesef ülkemizde de sigara kullanım yaşının giderek düştüğü gözlenmektedir (Zerin ve diğ., 2010).

Nikotin bağımlılığı "kullanılan bir psikoaktif maddeye kişinin daha önceden değer verdiği diğer uğraşlardan ve nesnelerden belirgin olarak daha yüksek bir öncelik tanıma davranışı” olarak açıklanmaktadır (Kesim, 2004). Nikotin bağımlılığı, sigara içiminin sürdürülmesinde ve hatta tedavi sürecindeki cevapların başarısızlığında rol oynayan en önemli faktördür. Bu sebeple nikotin bağımlılığı ile mücadele etmek bu anlamda çok önemlidir (Okutan, Taş, Kaya ve Kartaloğlu, 2007). Sigarayı bırakma kliniklerinin tedavi planlanmalarında en yaygın olarak Fagerstrom Nikotin Bağımlılık Testi (FNBT) kullanılmaktadır. Bu test birçok ülkede uyarlama çalışması yapılan ve kullanılan bir değerlendirme aracıdır (Uysal ve diğ., 2004; Saad-Hussein ve diğ., 2017; Klinsophon ve diğ., 2017; Berlin ve diğ., 2016).

Bir günde içilen sigara sayısı ile kardiyovasküler mortalite ve morbidite arasında doz bağımlı bir ilişki vardır (Hallstrom ve diğ., 1986; Alyan ve diğ., 2008). Ayrıca sigara kullanımının yaşam kalitesine olan etkisinin değerlendirilmesi için yapılan Lineer Regresyon analizinde sadece günde içilen sigara sayısının yaşam kalitesini azalttığı bulunmuştur (Kartal ve diğg., 2012). İngiltere'de bir günde içilen sigara sayısını etkileyen sosyo-ekonomik ve bireysel faktörleri sayma veri modelleriyle yapılan çalışmada sosyal etkileşimin bir günde içilen sigara sayısını azalttığı sonucuna ulaşılmış olsa da çalışan bireylerin daha fazla sigara içme eğiliminde olması sonucunun da sosyal etkileşimin etkisini yansıttığı bildirilmiştir (Kılıç, 2014). Sigara bırakma polikliniğine başvuran kişilerle yapılan araştırmada günde içilen sigara sayısı diğer araştırma gruplarına göre daha fazla tespit edilmiştir (Esen ve Arıca, 2018). 
Yapılan araştırmalarda günde içilen sigara sayısı ile Fagerstrom nikotin bağımlılık puanı arasında doğru orantı olduğu bildirilmiştir (Argüder ve diğ., 2013; Etter ve diğ., 1999). Diğer bir araştırmada ise günde içilen sigara sayısının nikotin bağımlılığın etkileyen faktörlerden biri olduğu sonucuna varılmıştır (Okutan ve diğ., 2007). Bu araştırmalarda yazarlar günde içilen sigara sayısının gruplar arasında farklılık gösterdiğini belirtirken Fagerstrom bağımlılık skorları arasındaki benzerliğin skorlamada kullanılan diğer değişkenlerin etkisinden kaynaklanabileceğini belirtmişlerdir (Argüder ve diğ., 2013). Günde içilen sigara sayısının hs-CRP düzeyine etkisinin incelendiği çalışmada sigaranın akut etkisinin yanında inflamasyon üzerindeki etkisinin kümülatif olduğu belirtilmiştir (Alyan ve diğ., 2008).

Gençler ile yapılan araştırmalarda solunum fonksiyonları ile fiziksel aktivite alışkanlıkları arasında bir ilişkinin olduğuna dair net bir kanıt bulunamadığı bildirilmiştir (Smith ve diğ., 2016). Daha yüksek düzeyde nikotin bağımlılığı ve nargile kullanımı bildiren gençlerin, sigara içmelerini kontrol etmek ve azaltmak için etkili stratejilerin belirlenmesi gerektiği ve uygulanmasında da ek yardıma ihtiyaç duyulduğu belirtilmiştir (Alzyoud ve diğ., 2020). Başka bir araştırmada fiziksel aktivitenin sıklı̆̆ ile günde içilen sigara sayısı ilişkilendirilmiş ve sonuç olarak da günde içilen sigara sayısının bireysel spor yapan gençlerde daha yaygın olduğu belirtilirken, sigara içenlerin hiç sigara içmeyenlere göre sporu daha erken bıraktığı vurgulanmıştır (Holmen ve diğ., 2002).

Alanyazı taraması sonucunda gençler arasında sigara içiminin yaygınlığı birçok araştırmada ele alınmasına rağmen spor yapan genç popülasyonda günde içilen sigara sayısına göre nikotin bağımlılığının ve solunum fonksiyonlarının karşılaştırılması ile ilgili araştırmalara rastlanmamıştır. Bu nedenle gençlerde günde içilen sigara sayısına göre ayrılan iki grubun nikotin bağımlılığında ve solunum fonksiyonlarında farklılık olup olmadığı merak edilmiştir. Çalışmanın hipotezi 'günde içilen sigara sayısı arttıkça nikotin bağımlılık puanı ve solunum kapasitesi artar’ şeklinde belirlenmiştir. Bu doğrultuda çalışmanın amacı gençlerde günde içilen sigara sayısına göre nikotin bağımlılığının ve solunum fonksiyonlarının karşılaştııılmasıdır.

\section{YÖNTEM}

\section{Araştırma Grubu}

Araştırmaya beden eğitimi ve spor yüksekokulunda eğitim gören 15 kadın ve 15 erkek toplam 30 öğrenci gönüllü olarak katılmıştır. Örneklem büyüklüğünün belirlenmesinde, Nikotin Bağımlılığı Testinde toplamda 6 madde bulunması ve ölçeklerdeki her madde için en az 5 birey olması gerektiği hususları göz önünde bulundurulup 30 örneklem sayısının madde sayısına göre de uygun olduğu düşünülmüştür (Kass ve Tinsley, 1979).

Çalışmaya katılan öğrencilerin yaş, vücut ağırlığı, boy uzunluğu, beden kitle indeksi ve günde içilen sigara sayısı ortalama ve standart sapma değerleri Tablo 1'de gösterilmiştir. 
Tablo 1. Öğrencilerin demografik bilgilerinin ortalamaları ve standart sapmaları

\begin{tabular}{|c|c|c|c|}
\hline & $\begin{array}{c}1-5 \text { içenler }(n=15) \\
\text { Ortalama } \pm S S\end{array}$ & $\begin{array}{c}6 \text { ve daha fazla içenler } \\
(n=15) \\
\text { Ortalama } \pm S S\end{array}$ & $\begin{array}{c}\text { Toplam }(n=30) \\
\text { Ortalama } \pm S S\end{array}$ \\
\hline Yaş (yll) & $19.60 \pm 0.51$ & $19.73 \pm 0.46$ & $19.67 \pm 0.48$ \\
\hline Vücut ağırlığı (kg) & $61.93 \pm 10.77$ & $63.80 \pm 10.01$ & $62.87 \pm 10.26$ \\
\hline Boy uzunluğu (cm) & $169.33 \pm 9.22$ & $169.53 \pm 7.09$ & $169.43 \pm 8.08$ \\
\hline Beden kitle indeksi $\left(\mathrm{kg} / \mathrm{m}^{2}\right)$ & $21.43 \pm 1.62$ & $22.13 \pm 2.77$ & $21.78 \pm 2.26$ \\
\hline Günde içilen sigara sayısı & $4.20 \pm 0.86$ & $9.73 \pm 2.46$ & $6.97 \pm 3.35$ \\
\hline
\end{tabular}

Çalışma; 2013 Helsinki Deklarasyonu Prensiplerine uygun olarak yapılmış ve bu çalışma için Haliç Üniversitesi Girişimsel Olmayan Klinik Araştırmalar Etik Kurulu’ndan onay alınmıştır (Etik no: 142-30.09.2019).

\section{Veri Toplama Araçları}

Kişisel Bilgi Formu: Araştırma grubunu belirlemek için öncelikle lisans öğrencilerine Google Form aracılı̆̆ıla çevrimiçi olarak kişisel bilgi formu ve sigara kullanımı ile ilgili sorular içeren anket gönderilmiştir. Anketin içeriğinde kişisel bilgi ve sağlık soruları bulunmaktadır. Anket sorularına toplam 167 kişi yanıt vermiş olup, 56 kişi sigara içtiğini belirtmiştir. Sigara içtiğini belirten 56 kişiden 30 kişi çalışmaya gönüllü olarak katılmayı kabul etmiştir. Araştırmaya herhangi bir üst solunum yolları hastalığı bulunan veya düzenli ilaç kullanan kişiler alınmamıştır.

Solunum Fonksiyonları: Katılımcıların solunum fonksiyon testleri taşınılabilir COSMED-Pony FX marka spirometre ile yapılmıştır. Katılımcılar ölçümlerin tamamında oturur pozisyondadır ve katılımcıların burnu bir kıskaçla kapatılmıştır. Sadece kişiye ağızlık yardımıyla spirometreye bağlı bir şekilde soluk hacminde birkaç solunum yaptırılarak kişinin bu tip solunuma alışması beklenmiş olup daha sonrasında ise test gerçekleştirilmiştir. Her ölçüm 3 defa tekrar edilip en iyi değer kaydedilmiştir (Beam ve Adams, 2013). Bu çalışmada, katılımcıların solunum fonksiyon testleri aracılı̆̆gyla zorlu vital kapasite (FVC), zorlu ekspirasyon hacmi (FEV1) ve tepe akım hızı (PEF) parametreleri ölçülmüştür. Çalışma, Haliç Üniversitesi Spor Bilimleri Araştırma ve Uygulama Laboratuvarında gerçekleştirilmiştir.

FNBT: Nikotin bağımllık düzeyini ölçen FNBT’nin, Uysal ve arkadaşları tarafından 2004 yılında "Fagerstrom test for nicotine dependence: Reliability in a Turkish sample and factor analysis" (Fagerstrom nikotin bağımlılık testininin Türkçe versiyonunun güvenirliği ve faktör analizi) adlı çalışma ile Türkçe geçerlik ve güvenirliği yapılmıştır. FNBT 6 soru içermektedir ve elde edilen toplam puanlara göre kişinin nikotin bağımlılığı çok az (0-2 puan), az (3-4 puan), orta (5 puan), yüksek (6-7 puan), çok yüksek (8-10 puan) şeklinde beş ayrı kategoriden oluşmaktadır (Uysal ve diğ., 2004). Çalışma öncesinde birinci yazardan gerekli izinler alınmıştır.

Tüm ölçümler yapıldıktan sonra araştırma grubu günde içilen sigara sayısına göre günde 1-5 sigara içenler ve günde 6 ve daha fazla içenler olmak üzere ikiye ayrılmıştır. 


\section{Verilerin Analizi}

Veriler SPSS IBM 24.0 programında değerlendirilmiştir. Verilerin normal dağılıp dağılmadığı Shapiro-Wilk testi ile değerlendirilmiştir. Bu doğrultuda cinsiyetler ve gruplar arası farklılık için non-parametrik test olan Mann-Whitney U testi; çoklu değişkenlerin değerlendirilmesi için ise çoklu lineer regresyon tercih edilmiştir. Anlamlılık düzeyi $\mathrm{p}<0.05$ olarak belirlenmiştir.

\section{BULGULAR}

Tablo 2. Gruplar arası günde içilen sigara sayısının nikotin bağımlılığına ve solunum fonksiyon parametrelerine etkisi

\begin{tabular}{|c|c|c|c|c|c|c|c|c|c|c|c|c|c|c|c|}
\hline & \multicolumn{5}{|c|}{$1-5$ içenler $(n=15)$} & \multicolumn{5}{|c|}{6 ve daha fazla içenler $(n=15)$} & \multicolumn{5}{|c|}{ Toplam $(n=30)$} \\
\hline & \multirow{2}{*}{$\begin{array}{l}\begin{array}{c}\text { Kadın } \\
(\mathrm{n}=8)\end{array} \\
\text { Min- } \\
\text { Max }\end{array}$} & \multirow{2}{*}{\begin{tabular}{|c|}
$\begin{array}{c}\text { Erkek } \\
(\mathrm{n}=7)\end{array}$ \\
Min- \\
Max
\end{tabular}} & \multicolumn{3}{|c|}{ Cinsiyetler arası } & \multirow{2}{*}{$\begin{array}{c}\begin{array}{c}\text { Kadın } \\
(\mathbf{n}=7)\end{array} \\
\text { Min- } \\
\text { Max }\end{array}$} & \multirow{2}{*}{ 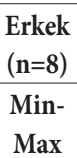 } & \multicolumn{3}{|c|}{ Cinsiyetler arası } & \multirow{2}{*}{$\begin{array}{c}\begin{array}{c}\text { Kadin } \\
(\mathrm{n}=15)\end{array} \\
\text { Min- } \\
\text { Max }\end{array}$} & \multirow{2}{*}{$\begin{array}{c}\begin{array}{c}\text { Erkek } \\
(\mathrm{n}=15)\end{array} \\
\text { Min- } \\
\text { Max }\end{array}$} & \multicolumn{3}{|c|}{ Gruplar arası } \\
\hline & & & $\mathbf{R}$ & $\mathbf{R}^{2}$ & $\underset{\text { değeri }}{p}$ & & & $\mathbf{R}$ & $\mathbf{R}^{2}$ & $\underset{\text { değeri }}{p}$ & & & $\mathbf{R}$ & $\mathbf{R}^{2}$ & $\underset{\text { değeri }}{p}$ \\
\hline $\begin{array}{l}\text { FVC } \\
\text { (L) }\end{array}$ & $\begin{array}{c}3.12- \\
4.16\end{array}$ & $\begin{array}{l}4.42- \\
6.60\end{array}$ & & & 0.584 & $\begin{array}{c}3.03- \\
4.38\end{array}$ & $\begin{array}{l}4.74- \\
5.53\end{array}$ & & & $0.001^{*}$ & $\begin{array}{c}3.03- \\
4.38\end{array}$ & $\begin{array}{c}4.42- \\
6.60\end{array}$ & & & 0.450 \\
\hline $\begin{array}{l}\text { FEV1 } \\
\text { (L) }\end{array}$ & $\begin{array}{c}2.68- \\
3.36\end{array}$ & $\begin{array}{c}3.68- \\
5.43\end{array}$ & 0.885 & 0.783 & 0.177 & $\begin{array}{l}1.74- \\
3.83\end{array}$ & $\begin{array}{c}3.02- \\
5.03\end{array}$ & 0.922 & 0.850 & 0.565 & $\begin{array}{l}1.74- \\
3.83\end{array}$ & $\begin{array}{c}3.02- \\
5.43\end{array}$ & 0.184 & 0.034 & 0.859 \\
\hline $\begin{array}{l}\text { PEF (L/ } \\
\text { sn) }\end{array}$ & $\begin{array}{c}4.00- \\
5.41\end{array}$ & $\begin{array}{c}5.22- \\
9.68\end{array}$ & & & 0.509 & $\begin{array}{c}2.52- \\
7.64\end{array}$ & $\begin{array}{c}4.15- \\
9.68\end{array}$ & & & 0.314 & $\begin{array}{c}2.52- \\
7.64\end{array}$ & $\begin{array}{c}4.15- \\
9.68\end{array}$ & & & 0.555 \\
\hline $\begin{array}{l}\text { FNBT } \\
\text { puanı }\end{array}$ & $\begin{array}{c}0.00- \\
4.00\end{array}$ & $\begin{array}{c}0.00- \\
3.00\end{array}$ & 0.031 & 0.001 & 0.913 & $\begin{array}{c}0.00- \\
4.00\end{array}$ & $\begin{array}{c}0.00- \\
4.00\end{array}$ & 0.076 & 0.006 & 0.787 & $\begin{array}{c}0.00- \\
4.00\end{array}$ & $\begin{array}{c}0.00- \\
4.00\end{array}$ & 0.350 & 0.123 & $0.048^{*}$ \\
\hline $\begin{array}{l}\text { Günde } \\
\text { içilen } \\
\text { sigara } \\
\text { sayısı }\end{array}$ & $\begin{array}{c}3.00- \\
5.00\end{array}$ & $\begin{array}{c}3.00- \\
5.00\end{array}$ & & & & $\begin{array}{l}7.00- \\
13.00\end{array}$ & $\begin{array}{l}7.00- \\
13.00\end{array}$ & & & & $\begin{array}{l}3.00- \\
13.00\end{array}$ & $\begin{array}{l}3.00- \\
13.00\end{array}$ & & & \\
\hline
\end{tabular}

${ }^{*}$ p $<0.05$ FVC: Zorlu Vital Kapasite; FEV1: Zorlu Ekspirasyon Hacmi; PEF: Tepe Akım Hızl; FNBT: Fagerstrom Nikotin Bağımlılık Testi

Gruplar arası günde içilen sigara sayısının nikotin bağımlılığına ve solunum fonksiyonlarına etkisi Tablo 2'de verilmiştir. Günde 1-5 tane sigara içen grubun solunum fonksiyonları ve nikotin bağımlılığında cinsiyete göre farklılık olmadığı tespit edilmiştir ( $p>0.05)$. Günde 6 ve daha fazla sigara içen grubun sadece FVC değerinde cinsiyetin günde içilen sigara sayısının nikotin bağımlılığında etkili olduğu belirlenmiştir $(\mathrm{p}<0.05)$. 
Tablo 3. Öğrencilerin solunum fonksiyon parametreleri ve FNBT puanlarının gruplar arası toplam karşılaştırılması

\begin{tabular}{|c|c|c|c|c|c|c|c|c|c|c|c|c|}
\hline & \multicolumn{4}{|c|}{$1-5$ içenler $(n=15)$} & \multicolumn{4}{|c|}{6 ve daha fazla içenler $(n=15)$} & \multicolumn{4}{|c|}{ Toplam $(n=30)$} \\
\hline & $\begin{array}{c}\text { Kadın } \\
(n=8)\end{array}$ & $\begin{array}{l}\text { Erkek } \\
(\mathbf{n}=7)\end{array}$ & $\begin{array}{r}\text { Cinsi } \\
\text { ar }\end{array}$ & $\begin{array}{l}\text { yetler } \\
\text { ası }\end{array}$ & $\begin{array}{l}\text { Kadın } \\
(n=7)\end{array}$ & $\begin{array}{c}\text { Erkek } \\
(\mathrm{n}=8)\end{array}$ & $\begin{array}{r}\text { Cins } \\
\text { ar }\end{array}$ & $\begin{array}{l}\text { iyetler } \\
\text { ası }\end{array}$ & $\begin{array}{l}\text { Kadın } \\
(n=15)\end{array}$ & $\begin{array}{c}\text { Erkek } \\
(n=15)\end{array}$ & Grupla & ar arası \\
\hline & $\begin{array}{l}\text { Ort } \pm \text { SS- } \\
\text { Medyan }\end{array}$ & $\begin{array}{l}\text { Ort } \pm \text { SS- } \\
\text { Medyan }\end{array}$ & $\mathrm{Z}$ & $\begin{array}{c}p \\
\text { değeri }\end{array}$ & $\begin{array}{l}\text { Ort } \pm S S- \\
\text { Medyan }\end{array}$ & $\begin{array}{l}\text { Ort } \pm \text { SS- } \\
\text { Medyan }\end{array}$ & $\mathrm{Z}$ & $\begin{array}{c}p \\
\text { değeri }\end{array}$ & $\begin{array}{l}\text { Ort } \pm S S- \\
\text { Medyan }\end{array}$ & $\begin{array}{l}\text { Ort } \pm \text { SS- } \\
\text { Medyan }\end{array}$ & $\mathrm{Z}$ & $\begin{array}{c}p \\
\text { değeri }\end{array}$ \\
\hline FVC (L) & $\begin{array}{c}3.52 \pm 0.34- \\
3.48\end{array}$ & $\begin{array}{c}5.22 \pm 0.71- \\
5.10\end{array}$ & & & $\begin{array}{c}3.55 \pm 0.45- \\
3.48\end{array}$ & $\begin{array}{c}5.09 \pm 0.28- \\
5.04\end{array}$ & & & $\begin{array}{c}3.53 \pm 0.38- \\
3.48\end{array}$ & $\begin{array}{c}5.15 \pm 0.51- \\
5.05\end{array}$ & & \\
\hline $\begin{array}{c}\text { FEV1 } \\
(\mathrm{L})\end{array}$ & $\begin{array}{c}2.94 \pm 0.23- \\
2.96 \\
\end{array}$ & $\begin{array}{c}4.51 \pm 0.63- \\
4.50\end{array}$ & $\begin{array}{l}-3.240 \\
-3.240\end{array}$ & $0.001^{*}$ & $\begin{array}{c}2.83 \pm 0.70- \\
2.79\end{array}$ & $\begin{array}{c}4.29 \pm 0.67- \\
4.57\end{array}$ & $\begin{array}{l}-3.240 \\
-2.777\end{array}$ & $\begin{array}{l}0.001^{*} \\
0.005^{\star}\end{array}$ & $\begin{array}{c}2.89 \pm 0.49- \\
2.90\end{array}$ & $\begin{array}{c}4.39 \pm 0.64- \\
4.52\end{array}$ & $\begin{array}{l}-0.249 \\
-0.062\end{array}$ & $\begin{array}{l}0.803 \\
0.950\end{array}$ \\
\hline $\begin{array}{c}\text { PEF (L/ } \\
\text { sn) }\end{array}$ & $\begin{array}{c}4.50 \pm 0.56- \\
4.29\end{array}$ & $\begin{array}{c}7.61 \pm 1.76- \\
8.35\end{array}$ & -2.777 & 0.005 & $\begin{array}{c}4.15 \pm 1.86- \\
4.05\end{array}$ & $\begin{array}{c}6.89 \pm 2.01- \\
7.48\end{array}$ & -2.548 & $0.011^{\star}$ & $\begin{array}{c}4.33 \pm 1.29 \\
4.10\end{array}$ & $\begin{array}{c}7.23 \pm 1.87- \\
8.15\end{array}$ & -0.539 & 0.590 \\
\hline $\begin{array}{l}\text { FNBT } \\
\text { puanı }\end{array}$ & $\begin{array}{c}1.38 \pm 1.51- \\
1.00\end{array}$ & $\begin{array}{c}1.29 \pm 1.60- \\
0.00\end{array}$ & -0.308 & 0.758 & $\begin{array}{c}2.29 \pm 1.60- \\
3.00\end{array}$ & $\begin{array}{c}2.50 \pm 1.41- \\
3.00\end{array}$ & -0.246 & 0.806 & $\begin{array}{c}1.80 \pm 1.57- \\
2.00\end{array}$ & $\begin{array}{c}1.93 \pm 1.58- \\
3.00\end{array}$ & -1.869 & 0.062 \\
\hline $\begin{array}{l}\text { Günde } \\
\text { içilen } \\
\text { sigara } \\
\text { sayısı }\end{array}$ & $\begin{array}{c}4.25 \pm 0.89- \\
4.50\end{array}$ & $\begin{array}{c}4.14 \pm 0.90- \\
4.00\end{array}$ & -0.249 & 0.803 & $\begin{array}{c}9.14 \pm 2.67- \\
8.00\end{array}$ & $\begin{array}{c}10.25 \pm 2.31- \\
10.00\end{array}$ & -1.006 & 0.314 & $\begin{array}{c}6.87 \pm 3.54- \\
5.00\end{array}$ & $\begin{array}{c}7.67 \pm 3.96- \\
7.00\end{array}$ & -4.720 & $0.000^{\star}$ \\
\hline
\end{tabular}

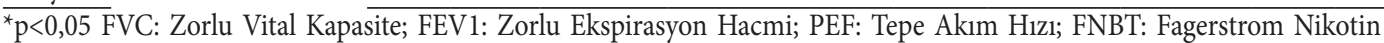
Bağımlılık Testi

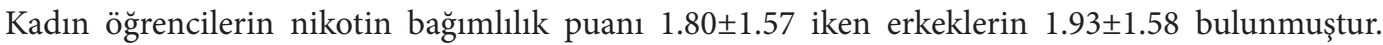
Solunum fonksiyon parametrelerinde cinsiyetler arası farklılık bulunurken $(\mathrm{p}<0.05)$, FNBT puanında ve günde içilen sigara sayısında cinsiyetler arası farklılığa rastlanmamıştır ( p>0.05). FVC, FEV1, PEF değerlerinde ve nikotin bağımlılık puanlarında gruplar arası anlamlı farklılığa rastlanmamışken ( $\mathrm{p}>0.05)$, günde içilen sigara sayısında gruplar arası anlamlı farklılık tespit edilmiştir $(\mathrm{p}<0.05)$ (Tablo 3.).

Tablo 4. Kadın ve erkek öğrencilerin solunum fonksiyon parametreleri ve FNBT puanlarının gruplar arası karşılaştırılması

\begin{tabular}{|c|c|c|c|c|}
\hline & \multicolumn{2}{|l|}{$\operatorname{Kadın}(n=15)$} & \multicolumn{2}{|l|}{ Erkek $(n=15)$} \\
\hline & $Z ; p$ & $\mathbf{p}$ & $Z ; p$ & p \\
\hline FVC (L) & $0.000 ; 1.000$ & 0.544 & $-0.174 ; 0.862$ & 0.967 \\
\hline FEV1 (L) & $-0.347 ; 0.728$ & 0.938 & $-0.174 ; 0.862$ & 0.914 \\
\hline $\operatorname{PEF}(\mathrm{L} / \mathrm{sn})$ & $-1.043 ; 0.297$ & 0.675 & $-0.985 ; 0.324$ & 0.741 \\
\hline FNBT puanı & $-1.023 ; 0.306$ & 0.277 & $-1.525 ; 0.127$ & 0.143 \\
\hline Günde içilen sigara sayısı & $-3.294 ; 0.001^{*}$ & & $-3.264 ; 0.001^{*}$ & \\
\hline
\end{tabular}

Kadın öğrencilerin FVC, FEV1 ve PEF değerleri ile FNBT puanlarında gruplar arası istatistiksel olarak anlamlı farklılık tespit edilmemiştir ( $p>0.05)$. Kadın ve erkek öğrencilerin günde içilen sigara sayısında gruplar arası anlamlı farklılığa rastlanmıştır ( $\mathrm{p}<0.05$; Tablo 4.). 


\section{TARTIŞMA ve SONUÇ}

Yapılan bu çalışmada beden eğitimi ve spor yüksekokulunda eğitim gören ve sigara içen öğrencilerin zorlu vital kapasiteleri üst seviyede bulunmuştur. Ayrıca, öğrenciler FNBT puanına göre çok az bağımlı ve az bağımlı olarak tespit edilmiştir. Bunun yanı sıra, solunum fonksiyon parametrelerinde cinsiyetler arası farklılık bulunup $(\mathrm{p}<0.05)$ günde 6 ve daha fazla sigara içen öğrencilerin ise FVC, FEV1 ve PEF değerleri daha düşük olduğu gözlenmiştir.

Sigara içen bireylerin nikotin bağımlılı̆̆ının değerlendirilmesinde kullanılan FNBT'yi içeren araştırmalar alanyazında incelendiğinde cinsiyete göre karşılaştırma çalışmalarına rastlanmıştır (Moreno-Coutiño ve Villalobos-Gallegos, 2017; Svicher ve diğ., 2018). Moreno-Coutiño ve Villalobos-

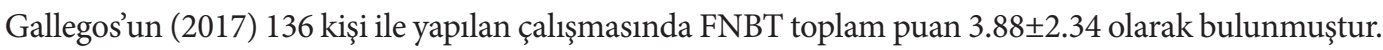
Svicher ve arkadaşlarının (2018) 869 kişi ile yaptıkları çalışmada ise FNBT toplam puan kadınlarda 3.62 \pm 2.36 ; erkeklerde 4.20 \pm 2.47 bulunmuş ve cinsiyetler arası farklılığa rastlanmıştır ( $\mathrm{p}<0.05)$. Tunç ve Kolburan’ın (2018) yaptıkları çalışmada nikotin bağımlılı̆̆ının erkek öğrencilerde kadınlara göre daha yüksek olduğu saptanmıştır ve babası sigara içen öğrencilerde sigara içme bağımlılığının daha yüksek olduğu bildirilmiştir. Çaykara ve arkadaşlarının İstanbul'da bir devlet hastanesinde, sigara bırakma biriminde başvuran 109 sigara bağımlısı (\%78,9'unu erkek ve \%21,1'ini kadın) üzerinde yaptıkları çalışmada; nikotin bağımlılı̆̆ının orta düzeyde (4.63 22.41) olduğu ve anksiyete, depresyon, bağımlılık, umutsuzluk düzeyleri arasında anlamlı ilişki olduğu (p凶0.01) tespit edilmiştir (Çaykara ve diğ., 2019).

Egzersiz yapmanın uyku düzenine ve FNBT puanına olan etkisinin incelendiği çalışmada ( $\mathrm{n}=20$ kadın+12 erkek) FNBT toplam puanı 3.6 \pm 0.4 tespit edilmiş; sigara içenlerin düşük uyku kalitesine sahip olduğu açıklanmıştır (Purani ve diğ., 2019). 20 kadın ve 14 erkek ile yapılan başka bir çalışmada, FNBT toplam puan 5.1 \pm 1.8 tespit edilmiş; FNBT’nin günde tüketilen sigara sayısı ile önemli ölçüde ilişkili olduğu vurgulanmıştır (Salhi ve diğ., 2021). Yalçın ve Ünal’ın yaptıkları çalışmada erkek grubun ( $n=190)$ FNBT puanı 6.0 \pm 2.2 ve kadın grubun $(n=122)$ FNBT puanı 5.6 \pm 2.1 hesaplanmıştır. Kişilerin sigara bırakma kararını almasında, bırakma esnasında ve bırakma sonrasında aile desteğinin ve sosyal desteğin her iki cinsiyet için önemli bir faktör olduğu ve bu konuda detaylı araştırmalara ihtiyaç duyulduğu vurgulanmıştır (Yalçın ve Ünal, 2019). Yurt-Öncel ve arkadaşlarının 2011 yılında sigara içen 548 lisans öğrencisiyle yaptıkları çalışmada; sigara içmenin bağlı olduğu faktörler incelenmiş, cinsiyet, ailede sigara içen sayısı, gelir düzeyi ve annenin eğitim düzeyinin rol oynadığını ve ebeveynlerin sigara içim sayısı ile sigaraya bağımlılık durumu arasında da pozitif ilişkinin olduğu belirtilmiştir (Yurt-Öncel ve diğ., 2011; Kartal ve diğ., 2012). Bizim bulgularımız sonucunda FNBT puanında grup içi cinsiyetler arası farklılık tespit edilmemiştir ( $\mathrm{p}>0.05)$.

Yapılan çalışmaların çoğunda havayolu obstrüksiyonunu belirlemek için FEV1 ve FEV1/FVC ölçümleri ölçüt olarak kullanılmaktadır ve pek çok araştırma sonucunda görülmüştürki tüm dünyada sigara içenler arasında görülen havayolu obstrüksiyonu bulguları, içmeyenler arasında görülenlerden sayıca çok daha yüksektir (Koçyiğit, 2002). Yapılan çalışmada sigara içme ile FVC, FEV1 değerleri arasında negatif yönde anlamlı bir ilişki olduğu bildirilmiştir (Demirbaş ve Kutlu, 2018). 40 yaş üzeri olan 372 kişi (\%53,8 kadın,

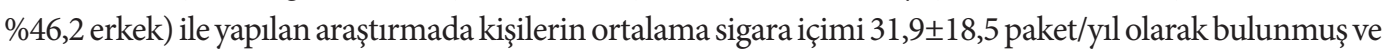


içilen sigara (hem paket/yıl hem de adet cinsinden) ile FEV1/FVC oranı arasında negatif ilişki saptanmıştır (Salepci, Havan, Fidan, Kıral ve Saraç, 2013). Bu bulguya destek olarak Demir ve arkadaşlarının yaptıkları bir çalışmada solunum fonksiyon testleri ile sigara kullanımı ilişkisi incelenmiş ve sigara içen 238 olgunun 23’ünde (\%9,7) FEV1/FVC oranı düşük olarak bulunmuştur (Demir ve diğ., 2006). Başka bir çalışmada bu oran \%16 değerinde sigara bırakma polikliniğine başvuran hastalarda da düşük bulunmuştur. PEF değerleri ortalamasının ise sigara içenlerde hiç içmeyenlere göre daha düşük olduğu saptanmıştır (Salepci ve diğ., 2013). Bilici ve Genç ise dört farklı grupla (sigara içen sporcu, sigara içmeyen sporcu, sigara içen sporcu olmayan, sigara içmeyen sporcu olmayan) yaptıkları çalışmada FVC, FEV1 ve PEF değerlerini sigara içmeyen sporcularda daha yüksek tespit etmişlerdir. Fiziksel aktivitenin solunum fonksiyonlarını iyileştirdiği buna karşın sigara bağımlılığının ise solunum fonksiyonlarını olumsuz etkilediği, iki faktörün de solunum fonksiyonları üzerinde önemli etkiye sahip olduğu vurgulanmıştır (Bilici ve Genç, 2020). Başka bir araştırmada günde içilen sigara sayısına göre gruplar incelenmiş ve günde 1-20 tane aralığında sigara içenlerin ( $n=108) 20$ taneden fazla içenlere göre $(n=49)$ FVC değeri 0.13; FEV1 değeri ise 0.55 daha yüksek bulunmuştur (Jawed, Ejaz ve Rehman, 2012). Tantisuwat ve Thaveeratitham (2014) yaptıkları çalışmada çoğu gencin günde içtiği sigara sayısının 10 taneden daha az olduğunu ve araştırma grubunun nikotin bağımlılı̆̆ı açısından az bağımlı derecesinde bulunduğunu belirtmişlerdir. Bu çalışmada sigara içen ve içmeyenlerin FVC farkı 0.39 iken FEV1 farkı 0.30 olarak tespit edilmiştir (Tantisuwat ve Thaveeratitham, 2014). Araştırmamızda günde 6 ve daha fazla sigara içen kişilerin FVC değerinde cinsiyetin etkisinin olduğu ( $\mathrm{p}=0.001)$ ve solunum fonksiyonlarında cinsiyetler arası farklılık bulunduğu ( $\mathrm{p}<0.05)$ saptanırken gruplar arası farklılık bulunmamıştır ( $\mathrm{p}>0.05)$.

Sonuç olarak, çalışmada Beden Eğitimi ve Spor Eğitimi alan öğrencilerin günde içtiği sigara sayısı arttıkça nikotin bağımlılığının da arttığı ve zorlu vital kapasitelerinin de olumsuz yönde etkilendiği söylenebilir.

Araştırmada kullanılan bağımlılık testinin derecelendirilmesi beş kategori üzerinden yapılmaktadır. Ancak bu çalışmada katılımcıların bağımlılık dereceleri; “çok az bağımlı” ve "azbağımlı" olduklarından değerlendirme sadece iki kategorik değişken üzerinden yapılmıştır. Bu durum çalışmada sınırlayıcı bir faktör olmuştur.

İleriki çalışmalarda, farklı yaş gruplarında ve farklı alanlarda öğrenim gören gençlerin nikotin bağımlılıkları ve solunum fonksiyon cevaplarının karşılaştırılması ile ilgili araştırmaların yapılması önerilebilir.

\section{KAYNAKLAR}

Alyan, Ö., Kaçmaz, F., Özdemir, Ö., Karahan, F., Taşkesen, T., İyem, H., Alan, S., Karadede, A. \& İlkay, D. (2008). Sigara içenlerde artmış yüksek duyarlıklı C-reaktif protein düzeyleri ve bozulmuş otonomik aktivite. Türk Kardiyoloji Derneği Araştırmaları, 36(6), 368-375. https://archivestsc.com/tr/jvi. aspx? $\mathrm{un}=\mathrm{TKDA}-47450$ \&volume $=36$ \&issue $=6$

Alzyoud, S., Veeranki, S. P. \& Pbert, L. (2020). Waterpipe tobacco smoking: nicotine dependence and smoking control strategies among youth. Journal of Substance Use, 25(5), 523-527. https://doi.org/10.1080/1465 9.891.2020.1738572 
Argüder, E., Karalezli, A., Hezer, H., Kılıç, H., Er, M., Hasanoğlu, H. C. \& Demir, P. (2013). Sigara bırakma başarısını etkileyen faktörler. Türk Toraks Dergisi, 14(3), 81-87. https://doi.org/10.5152/ttd.2013.18

Beam, W., \& Adams, G. (2013). Exercise physiology laboratory manual. McGraw-Hill Higher Education.

Berlin, I., Singleton, E. G., \& Heishman, S. J. (2016). A comparison of the Fagerström test for cigarette dependence and cigarette dependence scale in a treatment-seeking sample of pregnant smokers. Nicotine \& Tobacco Research, 18(4), 477-483. https://doi.org/10.1093/ntr/ntv108

Bilici, M. F., \& Genç, A. (2020). The effects of smoking addiction and physical activity on some respiratory functions in female university students. Pedagogy of Physical Culture and Sports, 24(2), 54-58. https:// doi.org/10.15561/26649.837.2020.0201

Çaykara, B., Tuna, R., Sağlam, Z. A., \& Pençe, H. H. (2019). Sigara bağımlılarında depresyon, umutsuzluk ve anksiyete düzeyleri arasındaki ilişkinin belirlenmesi. İzmir Göğüs Hastanesi Dergisi, 33(1), 15-23.

Demir, A., Büyükşirin, M., Polat, G., Kömürcüoğlu, B., Tekgül, S., Demirci, F., Katgı, N., Usalan, A., Eren, A., Köse, T., Güçlü, S. Z., \& Erdinç E. (2006). KOAH çadırında ölçülen SFT sonuçları ve KOAH risk faktörlerinin değerlendirilmesi. Toraks Dergisi, 7(1), 23-28.

Demirbaş, N., ve Kutlu, R. (2018). Sigaranın akciğer yaşı ve solunum fonksiyon testleri üzerine olan etkisi. Cukurova Medical Journal, 43(1), 155-163. https://doi.org/10.17826/cumj.342048

Esen, A. D., ve Arıca, S. (2018). Sigarayı bırakmak için başvuranlarda nikotin bağımlılık düzeyi ve sosyodemografik özelliklerin değerlendirilmesi. Ankara Medical Journal, 18(3), 328-336. https://doi. org/10.17098/amj.461371

Etter, J. F., Duc, T. V., \& Perneger, T. V. (1999). Validity of the Fagerstrom test for nicotine dependence and of the heaviness of smoking index among relatively light smokers. Addiction, 94, 269-81. https://doi. org/10.1046/j.1360-0443.1999.942.26910.x

Hallstrom, A. P., Cobb, L. A., \& Ray, R. (1986). Smoking as a risk factor for recurrence of sudden cardiac arrest. New England Journal of Medicine, 314, 271-275. https://doi.org/10.1056/NEJM198.601.303140502

Holmen, T. L., Barrett-Connor, E., Clausen, J., Holmen, J., \& Bjermer, L. (2002). Physical exercise, sports, and lung function in smoking versus nonsmoking adolescents. European Respiratory Journal, 19(1), 8-15. https://doi.org/10.1183/09031936.02.00203502

Jawed, S., Ejaz, S., \& Rehman R. (2012). Influence of smoking on lung functions in young adults. Journal of the Pakistan Medical Association, 62(8), 772-775.

Karlıkaya, C., Öztuna, F., Solak, Z. A., Özkan, M., \& Örsel, O. (2006). Tütün kontrolü. Türk Toraks Dergisi, 7(1), 51-64.

Kartal, M., Midik, Ö., \& Büyükakkuş, A. (2012). Ondokuz Mayıs Üniversitesi Tip Fakültesi öğrencilerinde sigara kullanımı ve yaşam kalitelerine etkisi. Türk Toraks Dergisi, 13(1), 11-7. https://doi.org/10.5152/ ttd.2012.03

Kass, R. A., \& Tinsley, H. E. A. (1979). Factor analysis. Journal of Leisure Research, 1, 120-138.

Kesim, Y. (2004). Sigaranın farmakolojik etkileri. Tür A (editör). Sigaranın bilimsel yüzü. İstanbul: Logos Yayıncilik.

Kılıç, D. (2014). Sigara Tüketiminin Panel Veri Analizi: İngiltere İçin Bir Uygulama. Gazi Üniversitesi İktisadi ve İdari Bilimler Fakültesi Dergisi, 16(3), 128-142.

Klinsophon, T., Janwantanakul, P., \& Thaveeratitham, P. (2017). Reliability of the Thai version of the Fagerstrom Test for Nicotine Dependence (FTND). Journal of the Medical Association of Thailand, 100(10), 1130-4.

Koçyiğit, E. (2002). Akciğer hastalıkları. İstanbul: Alemdar Ofset. 
Moreno-Coutiño A., \& Villalobos-Gallegos L. (2017). Psychometric properties of the Fagerström Test for Nicotine Dependence in a sample of mexican smokers. Journal of Addictions Nursing, 28(1), 27-33. https://doi.org/10.1097/JAN.000.000.0000000156

Okutan, O., Taş, D., Kaya, H., \& Kartaloğlu, Z. (2007). Sigara içen sağlık personelinde nikotin bağımlılık düzeyini etkileyen faktörler. Tüberküloz ve Toraks Dergisi, 55(4), 356-363.

Purani, H., Friedrichsen, S., \& Allen, A. M. (2019). Sleep quality in cigarette smokers: Associations with smoking-related outcomes and exercise. Addictive Behaviors, 90, 71-76. https://doi.org/10.1016/j. addbeh.2018.10.023

Saad-Hussein, A., Mohammed, A. M., Hafez, S. F., El-Tahlawy, E., Shaheen, W., Helmy, M. A., \& El-Hamshary, M. (2017). Environmental and social factors influencing in nicotine dependence detected through using Fagerström Test for Nicotine Dependence. Egyptian Journal of Environmental Research, 6, 68-76.

Salepci, B. M., Havan, A., Fidan, A., Kıral, N., \& Saraç, G. (2013). Sigara bırakma polikliniğinin KOAH ve küçük hava yolu hastalığının erken tespitine katkısı. Solunum, 15(2), 100-4. https://doi.org/10.5152/ solunum.2013.018

Salhi, L., Seidel, L., Albert, A., \& Lambert, F. (2021). Fagerström test for nicotine dependence as an indicator in tobacco-related studies in periodontology. Journal of Periodontology, 92, 298-305. https://doi. org/10.1002/JPER.20-0019

Smith, M. P., von Berg, A., Berdel, D., Bauer, C. P., Hoffmann, B., Koletzko, S., Nowak, D., Heinrich, J., \& Schulz, H. (2016). Physical activity is not associated with spirometric indices in lung-healthy German youth. European Respiratory Journal, 48(2), 428-440. https://doi.org/10.1183/13993.003.01408-2015

Svicher, A., Cosci, F., Giannini, M., Pistelli, F., \& Fagerström, K. (2018). Item response theory analysis of Fagerström test for cigarette dependence. Addictive Behaviors, 77, 38-46. https://doi.org/10.1016/j. addbeh.2017.09.005

Tantisuwat, A., \& Thaveeratitham, P. (2014). Effects of smoking on chest expansion, lung function, and respiratory muscle strength of youths. Journal of Physical Therapy Science. 26(2), 167-170. https://doi. org/10.1589/jpts.26.167

Thacher, J. D., Schultz, E. S., Hallberg, J., Hellberg, U., Kull, I., Thunqvist, P., Pershagen, G., Gustafsson, P. M., Melén, E., \& Bergström, A. (2018). Tobacco smoke exposure in early life and adolescence in relation to lung function. European Respiratory Journal, 51(6), 1-9. https://doi.org/10.1183/13993.003.02111-2017

Tunç, Z., ve Kolburan, Ş. G. (2019). Ergenlik döneminde benlik saygısı ile sigara bağımlılı̆̆ı arasındaki ilişkinin incelenmesi. Aydin Insan ve Toplum Dergisi, 5(1), 55-70.

Uysal, M. A., Kadakal, F., Karşidağ, C., Bayram N. G., Uysal, O., \& Yilmaz, V. (2004). Fagerstrom test for nicotine dependence: reliability in a Turkish sample and factor analysis. Tüberküloz ve Toraks Dergisi, 52(2), 11521.

WHO Launches new report on global tobacco use trends. https://www.who.int/news/item/19-12-2019who-launches-new-report-on-global-tobacco-use-trends\#: :text=By\%202020\%2C\%20WHO\%20 projects\%20there,in\%20tobacco\%20use\%20since\%202010; Erişim Tarihi: 1.6.2021.

Yalçın, B. M., ve Ünal, M. (2019). Sigara bırakmada aile desteğinin ve sosyal desteğin ilk altı aylık dönemdeki etkisi. Turkish Journal of Family Medicine and Primary Care, 13(1), 52-59. https://doi.org/10.21763/ tjfmpc. 528022

Yurt-Öncel, S., Gebizlioğlu, Ö. L., \& Alioğlu, F. A. (2011). Risk factors for smoking behavior among university students. Turkish Journal of Medical Sciences, 41(6), 1071-1080. https://doi.org/10.3906/sag-1009-1122

Zerin, M., Karakılçık, A. Z., Cebeci, B., \& İriadam, M. (2010). Üniversite öğrencilerinde kısa ve uzun süre sigara içiminin bazı solunum parametreleri üzerine etkisi. Gaziantep Tip Dergisi, 16(3), 9-12. 